\title{
Insecure paternal attachment contributes to childhood anxiety
}

\author{
By Jessica K. Edwards
}

A recent study has investigated the direct and indirect relationships between parent-child attachment and negative parental behaviours exhibited by mothers and fathers, individually, in a sample of children with clinical anxiety. Sonja Breinholst and colleagues at the University of Copenhagen recruited 54 families to their study. They measured childhood anxiety symptoms (at a mean age 9.6 years) using the Spielberger Statetrait Inventory for Children and assessed attachment relationships and parental behaviours using the Security Scale and the Rearing Behavior Questionnaire, respectively. Consistent with previous research ${ }^{1}$, Breinholst et al. found no evidence to support that child-reported maternal attachment or maternal parenting behaviour could predict child-reported anxiety. Conversely, and in contrast to the researcher's previous study ${ }^{2}$, they did find that insecure attachment to fathers contributed to child-reported anxiety and fully mediated the relationship between paternal rejection and child anxiety. As highlighted in an accompanying commentary, these results are surprising as others have reported either the strongest effects for maternal variables ${ }^{3}$ or equal effects for both parents (Groh 2012) on child anxiety. More research is now needed to confirm whether fathers and mothers do have different roles on child developmental outcomes. Pending replication, the researchers suggest that paternal variables should be included in childhood anxiety assessments and that fathers should be included in the treatment of anxiety.

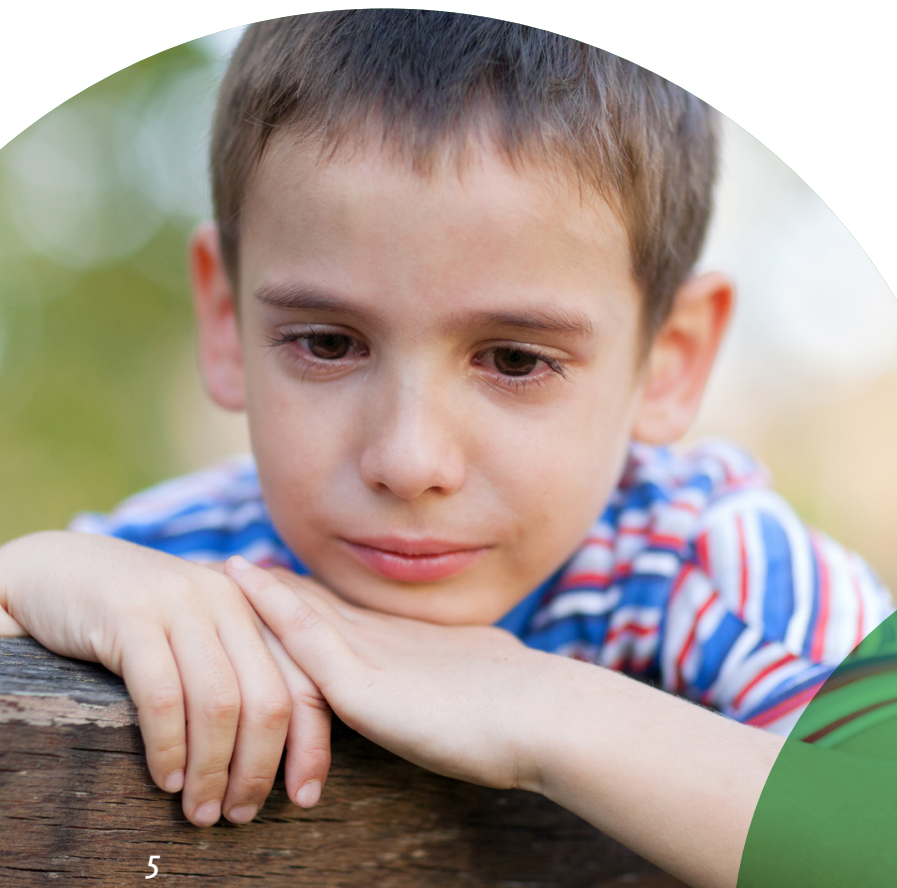

\section{Referring to:}

Breinholst, S., Tolstrup, M. \& Esbjørn, B.H. (2019), The direct and indirect effect of attachment insecurity and negative parental behaviour on anxiety in clinically anxious children: it's down to dad. Child Adolesc. Ment. Health. 24: 44-50. doi: 10.111/camh.12269.

\section{See also:}

Domoney, J. \& Nath, S. (2019), Commentary: The complexity of family dynamics in child anxiety disorder - a commentary on Breinholst et al. (2018). Child Adolesc. Ment. Health. 24: 51-53. doi: 10.111/camh.12283.

\section{References:}

${ }^{1}$ Hudson, J.L. et al. (2001), Parent-child interactions and anxiety disorders: An observational study.

Behav. Res. Ther. 39: 1411-1427.doi: 10.1016/s00057967(00)00107-8.

${ }^{2}$ Breinholst, S. et al. (2015), Effects of attachment and rearing behaviour on anxiety in normal developing youth: A mediational study. Pers. Individ. Differ. 81: 155-161. doi: 10.1016/j. paid.2014.08.022.

${ }^{3}$ Rothbaum, F. et al. (1995), Early parent-child relationships and later problem behavior: $A$ longitudinal study. Merill-palmer Quarterly, 41: 133-151.

${ }^{3}$ Groh, A.M. et al. (2012), The significance of insecure and disorganized attachment for children's internalizing symptoms: A meta-analytic study. Child Dev, 83: 591-610. doi: 10.1111/j.14678624.2011.01711.x. 